\title{
Vito Messina, Jafar Mehr Kian, "Return to Shami: Preliminary survey of the Iranian-Italian Joint Expedition in Khuzistan at Kal-e Chendar"
}

\section{Rémy Boucharlat}

\author{
(2) OpenEdition \\ Journals \\ Édition électronique \\ URL : http://journals.openedition.org/abstractairanica/47069 \\ DOI : 10.4000/abstractairanica.47069 \\ ISBN : 1961-960X \\ ISSN : 1961-960X \\ Éditeur : \\ CNRS (UMR 7528 Mondes iraniens et indiens), Éditions de l'IFRI
}

\section{Référence électronique}

Rémy Boucharlat, « Vito Messina, Jafar Mehr Kian, "Return to Shami: Preliminary survey of the IranianItalian Joint Expedition in Khuzistan at Kal-e Chendar" », Abstracta Iranica [En ligne], Volume 37-38-39 | 2018, document 70, mis en ligne le 30 décembre 2018, consulté le 30 septembre 2020. URL : http:// journals.openedition.org/abstractairanica/47069; DOI : https://doi.org/10.4000/abstractairanica. 47069

Ce document a été généré automatiquement le 30 septembre 2020.

Tous droits réservés 
Vito Messina, Jafar Mehr Kian, "Return to Shami: Preliminary survey of the Iranian-Italian Joint Expedition in Khuzistan at Kal-e Chendar"

Rémy Boucharlat 


\section{RÉFÉRENCE}

Vito Messina, Jafar Mehr Kian, "Return to Shami: Preliminary survey of the IranianItalian Joint Expedition in Khuzistan at Kal-e Chendar", Iran 52, 2014, p. 65-77.

Depuis 2008, une mission irano-italienne se consacre à l'étude cette région du Khuzestan, dite Elymaïde au cours de la période séleuco-parthe. Après l'étude minutieuse du bas-relief de Hung-e Azhdar (cf. dans ce numéro cr Vito Messina (ed.). Hung-e Azhdar. Research of the Iranian-Italian), la nouvelle phase du programme scientifique est Shami à $20 \mathrm{~km}$ au nord de ce relief, près de la ville modern d'Izeh (anc. Malamir). Il y a plus de 60 ans, Sir Aurel Stein avait révélé la fameuse statue parthe en bronze qu'il avait vue à Shami, ainsi que des objets remarquables provenant d'un bâtiment mal identifié, peut-être un temple.

2 Avant la fouille, l'étude du site a été conduite par l'étude des images satellitaires, photos aériennes, et prospection au sol. Un plan précis a été établi montrant plusieurs terrasses retenues par des murs de soutènement en moellons. Celle sur laquelle Stein avait fait des fouilles et trouvé des objets a été identifiée. Elle porte un ensemble bâti bien plus important que ce qu'il avait vu l'archéologue britannique. Le site est cependant gravement endommagé par les travaux agricoles modernes, ou par de nouvelles constructions.

\section{AUTEURS}

\section{RÉMY BOUCHARLAT}

UMR 5133 CNRS-Université de Lyon 